\title{
Big Fish and Other School Effects on Academic Self-Concept
}

\author{
William Strein \& Julie Grossman
}

\author{
University of Maryland, College Park
}

Presentation (Poster Session) at the Annual Convention of the American Psychological Association, San-Diego, August, 2010

Direct correspondence to: strein@umd.edu 


\title{
Big Fish and Other School Effects on Academic Self-Concept
}

\begin{abstract}
A substantial amount of research indicates that academic self-concept is a function of both individual characteristics, and school effects that impact on the development of selfperceptions. Few studies have studied a cohort of students as they progress through the transition from elementary to middle school. The present study uses multi-level modeling to examine school effects on students' academic self-concept in reading and math as they transition from elementary to middle school. Data come from the ECLS-K data set. Few school effects were found, but students' SES was found to be a strong moderator of the relationship between reading achievement and self-perceptions of students' ability and interest in reading.
\end{abstract}

Educational researchers increasingly have become attuned to the possibility of "school effects" on educational outcomes. "School effects" refers to the idea that various outcomes may be, in part, due to school-wide characteristics, over and above individual student or teacher characteristics. For example, Lee and Smith (1997) found that mid-size high schools produce larger achievement gains from students' freshman to senior years than do either small or large high schools, net of individual student characteristics, and that achievement in these schools was more equitably distributed across students' SES. Similarly, Lee and Smith (1996) found that high schools in which teachers, as a group, believed in collective responsibility for student achievement produced stronger achievement gains than did schools whose teachers, as a group, held different attitudes. "School effects" are just one example of an "ecological effect", in which features of the larger environment have demonstrable effects on various outcomes net of individual variables. The school psychology literature contains little research that truly explores ecological effects, although some recent studies (e.g., Rhodes, Roffman, Reddy, \& Fredriksen, 2004) have included such variables.

Testing for ecological effects also raises methodological issues. Most such research has used ordinary least-squares regression (OLS) to assess school effects net of individual variables through the straightforward practice of using ordered regression procedures in which individual student characteristics are entered as a block on the first step, and school-wide variables are entered on the second step. A significant increase in $\mathrm{R}^{2}$ then serves as the measure of school-wide variables while controlling for individual variables. Alternatively, one might use an ANOVA and use covariates to partial out various effects. While these procedures have intuitive appeal and are reasonably easily understood, Lee (2000) delineates the methodological shortcomings of this approach: (a) aggregation bias - in which the same variable (e.g., SES) may have different meanings at different levels of aggregation (e.g., individual vs. school levels), (b) non-independence of cases (e.g., an individual student's achievement may be related to the achievement levels of other students in the school), and (c) heterogeneity of regression.

To counter these shortcomings, researchers may use multi-level modeling (MLM) methodology that allows for the modeling all of these effects. The most commonly used statistical program for performing such analyses is Hierarchical Linear Modeling (HLM) (Raudenbush, Byrk, Cheong, Congdon, \& du Toit, 2004). Studies using HLM have begun to appear in the school psychology literature (Rhodes, et al., 2004; Stage, 2001). Most recently Clements, Bolt, Hoyt, and Kratochwill (2007) have championed the use of 
MLM methodology to study school-based interventions.

Research on school effects has focused primarily on achievement as outcomes, but such logic and analysis can be applied to social-emotional outcomes as well. Over a 20-year period, Herbert Marsh and his colleagues (e.g., Marsh \& Hau, 2003) have conducted a substantial amount of research investigating the effects of school average ability on student's academic self-concepts (ASC). Marsh and his co-workers discovered that school characteristics moderated the relationship between ASC and achievement. Humorously dubbed the "big-fish-little-pond effect (BFLPE)", Marsh found that students with the same academic achievement level had somewhat lower ASCs when embedded in schools with higher average student ability, although the effect size is relatively small. Other recent research has further explored school effects on ASC. Trautwein, Ludtke, Koller, and Baumert (2006) found that the learning environment moderates the development of self-concept for a set of seventh grade students. Specifically, "meritocratic" schools produced more accurate ASCs than did "ego-protective" school environments. School average ability and meritocratic structure are excellent examples of "school effects".

None of these studies, above, investigated the effects of school transition on academic self-concept. Numerous other studies have looked at such effects in relation to goals, classroom practices, teaching styles and foci, and social status. In general, research has found that students' academic self-concept declines during early adolescence and junior high school (Anderman \& Midgley, 1997; Cantin \& Boivin, 2004; Cole, 2001; Harter, Whitesell and Kowalski, 1992) which may be related to the change in atmosphere, change in teacher expectations, new grading practices, and a new social atmosphere. Harter, et al. investigated fifth through seventh graders experiencing school transitions and found that the effect of their academic self-concept was related to the transition as well as the anxiety and affect related to the transition. Wigfield, Eccles, Mac Iver, Reuman, and Midgley (1991) found that students' academic selfconcept declined between sixth and seventh grades while their perceptions of social ability increased during seventh grade.

Little research has focused on the possibility of school effects other than the BFLPE on academic selfconcept. Such school effects include the type of school (public or private), the size of the school, and the average socio-economic status of school. The goal of the present study was to extend the research on school effects on academic self-concept by tapping data from the recently released $8^{\text {th }}$ grade follow-up of students in the Early Childhood Longitudinal Study, Kindergarten cohort (ECLS-K). The $8^{\text {th }}$ grade follow-up allows for comparison of the influences on academic self-concept in elementary and middle school. Hierarchical linear modeling (HLM) methodology was used to address the following questions:

1. What individual and school effects are associated with academic self-concepts in 5th and 8th grade?

2. Are school effects on $8^{\text {th }}$ graders' academic self-concepts similar to those for $5^{\text {th }}$ graders, after accounting for individual child characteristics, particularly academic ability in reading and math?

3. Do students who transition from elementary to middle school with substantially higher (or lower) school-wide achievement experience changes in their self-perceptions of competence?

\section{Methodology}

\section{Samples}

The ECLS-K dataset is comprised of a base-year nationally stratified sample of 17,401 students who began kindergarten in Fall 1998. Data were collected at various points in students' kindergarten, first and third grade years, and in the spring semesters of 2004 and 2007 when most students were in the $5^{\text {th }}$ or $8^{\text {th }}$ 
grade, respectively. This study uses data from these $5^{\text {th }}$ and $8^{\text {th }}$ grade cohorts. Consistent with suggestions on the use of HLM methodology (Raudenbush \& Bryk, 2002), students were only selected if there were at least five students in the dataset from each school. Additionally, because we were interested in comparing the $5^{\text {th }}$ and $8^{\text {th }}$ grade models, only those students who were in their "correct" grade were included, i.e., those who may have been retained or advanced (9.8\% of the sample) were dropped. The resulting sample was comprised of 6699 fifth grade students from 802 elementary schools and 4577 students from 472 middle or K-8 schools. See Table 1 for demographic information on students; Table 2 for demographic information on schools.

\section{Measures}

Based on data available in the ECLS-K dataset and on the extant literature on ASC and its relationship with other variables, we chose to include five student-level measures in this study: reading and math ASC (separate dependent measures), tested reading and math achievement, student socio-economic status (SES), SES by achievement interaction, and gender. School-level variables included school-average achievement in reading or math, school-wide SES, proportion of minority students, school enrollment, and public or private school status.

Academic Self-Concept (ASC). The ECLS-K dataset includes two ASC subscales from the SelfDescription Questionnaire (SDQ) (Reading, Math), each having 4-8 Likert items, each with a 4-point scale. The SDQ is a widely-used research measure of self-concept with amply demonstrated reliability and validity. Reliabilities (alpha coefficients) for in the larger data set are excellent ( $5^{\text {th }}$ grade: $.83-.92$; $8^{\text {th }}$ grade: $\left..76-.89\right)$. The composite score for each scale is the average of the scale's items, such that the composite score can range from 1.00 to 4.00 . SDQ scores for $5^{\text {th }}$ grade were highly negatively skewed. To somewhat bring the distribution more toward a normal distribution, we reflected and inverted the scores prior to standardizing them.

Achievement. Achievement scores in reading and math are standardized T-scores resulting from direct assessments of the child. Extensive evidence supporting the tests' validity is reported in the ECLS-K manuals. Reported reliabilities for all fifth graders are excellent (reading: $5^{\text {th }}-.93,8^{\text {th }}-.87$; math: $5^{\text {th }}$ $\left..94,8^{\text {th }},-.92\right)$.

Socioeconomic Status (SES). The SES measure in the ECLS-K that we used is a composite based on parental education and occupation, and family income. This continuous measure is a standardized measure (z-score) ranging in the larger dataset from about +/- two standard deviations.

SES by Achievement Interaction. Based on the research of Trusty, Peck, and Matthews (1994) suggesting that there may be an SES by achievement interaction effect such that high SES/low achieving students have particularly low ASCs, we including this term in our student-level predictors. We crossed SES by either reading or math achievement, respectively, depending on the corresponding dependent variable under study.

Gender. Gender was dichotomously coded from the base-year student file. There are no missing data for this variable.

Imputation of Missing Data. Because student SES from the $3^{\text {rd }}, 5^{\text {th }}$, and $8^{\text {th }}$, grade years were highly intercorrelated, missing SES data at $5^{\text {th }}$ and $8^{\text {th }}$ grades was imputed by using the individual's previous SES data. A very small amount of SES data $(<1 \%)$ was still missing, and was imputed using the grand mean for $5^{\text {th }}$ or $8^{\text {th }}$ grade, respectively. Similarly, there was a very small amount $(<1 \%)$ of achievement and ASC data missing which was imputed using the respective grand mean. 
Standardization of Individual Level Variables. All of the continuous variables (two types of ASC, reading and math achievement, SES, and SES by achievement interaction were converted to Z-scores based on the samples of $5^{\text {th }}$ and $8^{\text {th }}$ grade students, respectively.

School Level Measures. Six school-level (i.e., characteristics of schools) measures were used as independent variables, and were simply the aggregated values (school-wide means) of individual students' standardized reading achievement, math achievement, and SES scores, each school's proportion of minority students in the sample, and the urbanicity status (urban, not urban) of the school.

\section{Data Analysis}

All analyses of individual student variables used data weighted by a normalized weight (C56CW0) from the ECLS-K that most closely corresponded to the subset of data that we used. Analyses were performed for three groups of subjects: (a) $5^{\text {th }}$ graders; (b) $8^{\text {th }}$ graders; (c) $8^{\text {th }}$ graders who changed schools since $5^{\text {th }}$ grade. Following descriptive analyses of all data (see Table 3 ), we performed a series of four HLM analyses separately for each of the two ASC independent variables, in the following order: (a) an Unconditional Model, used to establish a base for comparison and to assess the amount of variance due to "group effects"; (b) a Within-Schools Model in which only individual, student characteristics were modeled; (c) an Intercept-as-Outcome Model, which analyzed the relationships between hypothesized school characteristics and students' ASCs, net of student's between ASCs and student characteristics within schools; and (d) a Cross-Level Interaction Effects Model, which analyzed the effects of school-wide characteristics on relationships between ASCs and student characteristics within schools (also referenced in the literature as Slopes-as-Outcomes models).

\section{Results and Discussion}

A major goal of this study was to identify and compare individual and school-level effects on students' ASCs in late elementary school $\left(5^{\text {th }}\right.$ grade $)$ and middle school $\left(8^{\text {th }}\right.$ grade $)$. Although we did not focus on the question of changes in levels of ASC between the two age groups, we begin by noting that both reading and math ASCs were substantially lower for the students in their $8^{\text {th }}$ grade year than when they were in the $5^{\text {th }}$ grade. Eighth grade reading ASC was about .5 points (on a $1-5$ scale) lower than in $5^{\text {th }}$ grade; math ASC about .3 points lower. Indeed the $5^{\text {th }}$ grade ASCs were highly negatively skewed with a "perfect" score of 4 being the modal value, whereas $8^{\text {th }}$ grade were ASCs were clustered about the midpoint of the scale (2.5). See Table 3 for descriptive data. This is consistent with much of the research on the issue of transitions during this age period including, for example, the early work of Wigfield et al. (1991).

In general, few differences were found when examining the $5^{\text {th }}$ and $8^{\text {th }}$ grade models. See Table 4 for a summary of outcomes. At the individual level, our findings reflect those typically found in the literature. Actual achievement in reading and math were the strongest predictors of their respective self-concepts with beta coefficients in the .3 to .4 range for both age levels. ). These correlations are very similar to those found elsewhere in the literature. Marsh and Hau's (2003) cross-national study of ASC in 26 countries found a mean correlation of .38 between achievement and ASC. For both grades with respect to gender, girls had higher reading self-concepts than did boys when controlling for their actual academic achievement in each respective area. No gender effect was found for math ASC.

The most interesting finding at the individual level is with regards to SES. Generally, the literature indicates a positive relationship between SES and ASC (Rhodes et al., 2004). In an earlier study (Strein, Pickering, \& Grossman, 2009) we found no such relationship. Similarly, in the current study the relationship between SES and math ASC was non-significant at both grade levels, and reading ASC was 
significant only at the fifth grade level (see Table 4). When considering these findings, it is important to note that, given the methodology used, all of the coefficients relating individual student characteristics (within schools) to ASC exist within the context of one another. Indeed, statistically significant $(\mathrm{p}<.01)$, but small zero-order correlations $(.04-.16)$ were found between student SES and the ASC measures. However, research by Trusty, et al. (1994) suggested that the SES/ASC relationship is confounded by interactions between student SES and achievement, such that low-achieving, high-SES students are particularly vulnerable to having low ASCs. Given this possibility we included an SES x achievement (reading or math, respectively) variable in all of our models. For reading ASC this interaction term was significant $(\beta=.39 ; \mathrm{p}<.001)$ at the $5^{\text {th }}$ grade level and approached significance $(\beta=.32 ; \mathrm{p}=.07)$ for the $8^{\text {th }}$ graders who had changed schools since $5^{\text {th }}$ grade. Consistent with Trusty et al., students with higher family SES had substantially stronger relationships between reading achievement and reading ASC. Figure 1 displays this interaction effect for three levels of SES for $5^{\text {th }}$ grade students.

With regard to the school level, analyses from the unconditional model revealed that about $10 \%$ of the variance in academic self-concept was due to school-level effects. Although group effects were modest, these represent meaningful influence of ecological effects on students' ASCs. Surprisingly, few schoollevel effects were found, and those that were found were weak. Although we found some support for Marsh's BFLPE (gamma coefficients for all school-wide achievement variables were negative as the BFLPE would suggest), the effects were much lower than found elsewhere in the literature. In our earlier study using the ECLS-K $5^{\text {th }}$ grade data (\$Strein, et al., 2009) we found a coefficient of -.21 between school-wide achievement and both reading and math ASCs. Indeed, the magnitude of the BFLPE seems to be remarkably consistent across studies. In their multi-national study of ASCs in 26 countries Marsh and Hau (2003) found a composite effect of -.206, although there was significant variation across countries. Several studies within the US have found similar results. This is unexplained and deserves further exploration. One possibility is that our previous research (Strein, et al., 2009) included previous ASC in the model, whereas we did not do so here. The implication may be that ASC is so much of a intra-personal variable that school effects are observable only after subtracting out a stable personality-like trait. Additionally, we previously used only students in public schools and only those who had been in the same school for several years. School effects might reasonably be expected to be greater for those with longer history in the same school. It is also possible that students in non-public schools experience a "reflected glory" effect (Marsh, Kong, \& Hau, 2000) in which identification with being a member of a high-achieving schools boosts, rather than reduces, one's ASC.

Beyond school-wide achievement other school-level effects were either nonsignificant or trivial. No significant effects were found for school-wide SES, size (enrollment), or public/private status. The minority percentage of schools had a significant, but weak effect on reading ASC $(\gamma=.06 ; p<.05)$. Students in schools with higher percentages of minorities had slightly greater ASCs than for students in schools with fewer minorities, after considering the effects of individual and school-wide achievement.

HLM methodology allows for testing of "cross-level interactions", i.e., effects of school-level variables on the relationship between individual-level variables. Because we tested numerous such effects within each model, we chose an alpha level of .01 to determine statistical significance. Only two such interactions were found, but the results were consistent. At both the $5^{\text {th }}$ and $8^{\text {th }}$ grade levels, there was a small, positive $(.10, .14)$ cross-level interaction between school-average reading achievement and the slope relating individual reading achievement to reading ASC. In schools with higher reading achievement, there was a slightly stronger relationship between reading achievement and reading ASC. This phenomenon was not in evidence with regard to math ASC and math achievement. 


\section{References}

Anderman, E., \& Midgley, C. (1997). Changes in achievement goal orientations, perceived academic competence, and grades across the transition to middle-level schools. Contemporary Educational Psychology, 22, 269-298

Bouchley, H. \& Harter, S. (2005). Reflected appraisals, academic self perceptions, and math/science performance during early adolescence. Journal of Educational Psychology, 97, 673-686.

Clements, M. A., Bolt, D., Hoyt, W., \& Kratochwill, T. R. (2007). Using multilevel modeling to examine the effects of multitiered interventions. Psychology in the Schools, 44, 503-13.

Cantin, S., \& Boivin, M. (2004). Change and stability in children's social network and self-perceptions during transition from elementary to junior high school. International Journal of Behavioral Development, 28, 561-570.

Dai, D., \& Rinn, A. (2008). The Big-Fish-Little-Pond Effect: What do we know and where do we go from here?. Educational Psychology Review, 20, 283-317

Harter, S., Whitesell, N., \& Kowalski, P. (1992). Individual differences in the effects of educational transitions on young adolescents' perceptions of competence and motivational orientation. American Educational Research Journal, 29(4), 777-807.

Lee, V. E. (2000). Using hierarchical linear modeling to study social contexts: The case of school effects. Educational Psychologist, 35, 125-141.

Lee, V. E., \& Smith, J. B. (1996). Collective responsibility for learning and its effects on gains in achievement for early secondary school students. American Journal of Education, 104, 103-145.

Lee V. E., \& Smith, J. B. (1997). High school size: Which works best and for whom? Educational Evaluation and Policy Analysis, 19, 205-227.

Marsh, H. W., \& Hau, K-T. (2003). Big-fish-little-pond effect on academic self-concept: A cross-cultural (26-country) test of the negative effects of academically selective schools. American Psychologist, 58, 364-376.

Marsh, H. W., Kong, C. K., \& Hau, K. T. (2000). Longitudinal multilevel modeling of the big fish little pond effect on academic self-concept: Counterbalancing social comparison and reflected glory effects in Hong Kong high schools. Journal of Personality and Social Psychology, 78, 337-349.

Raudenbush, S. W. \& Bryk, A. S. (2002). Hierarchical linear models: Applications and data analysis methods, $2^{\text {nd }}$ Ed. Thousand Oaks, CA: Sage Publications.

Raudenbush, S., Byrk, A., Cheong, Y. F., Congdon, R., \& du Toit, M. (2004). HLM 6: Hierarchical linear and nonlinear modeling. [Computer software]. Lincolnwood, IL: Scientific Software International.

Rhodes, J., Roffman, J., Reddy, R., \& Fredriksen, K. (2004). Changes in self-esteem during the middle school years: A latent growth curve study of individual and contextual influences. Journal of School Psychology, 42, 243-261.

Stage, S. A. (2001). Program evaluation using hierarchical linear modeling with curriculum-based measurement reading probes. School Psychology Quarterly, 16, 91-112.

Strein, W., Pickering, C., \& Grossman, J. (2009). Urbanicity and academic self-concept. Paper (poster session) presented at the annual convention of the National Association of School Psychologists, Boston, MA, March.

Trautwein,U., Ludtke,O., Koller,O., \& Baumert, J. (2006). Self-esteem, academic self-concept, and achievement: how the learning environment moderates the dynamics of self-concept. Journal of 
Personality and Social Psychology, 90, 334-49.

Trusty, J., Peck, H.I., \& Matthews, J. (1994). Achievement, socioeconomic status and self-concepts of fourth-grade students. Child Study Journal, 24, 281-298.

Wigfield, A., Eccles, J., Mac Iver, D., Reuman, D., \& Midgley, C. (1991). Transitions during early adolescence: Changes in children's domain-specific self-perceptions and general self-esteem across the transition to junior high school. Developmental Psychology, 27(4), 552-565. 
Table 1: Student Demographics

\begin{tabular}{|c|c|c|c|c|}
\hline Demographic & $\mathrm{N}$ & $\%$ & $\mathrm{~N}$ & $\%$ \\
\hline & \multicolumn{2}{|c|}{ Fifth Grade } & \multicolumn{2}{|c|}{ Eighth Grade } \\
\hline Unweighted N & 6699 & ---- & 4760 & ---- \\
\hline \multicolumn{5}{|l|}{ Gender } \\
\hline Male & 3339 & 49.8 & 2293 & 50.1 \\
\hline Female & 3360 & 50.2 & 2284 & 49.9 \\
\hline \multicolumn{5}{|l|}{ Ethnicity } \\
\hline European-Am. & 4210 & 62.8 & 3233 & 70.6 \\
\hline African-Am. & 806 & 12.0 & 356 & 7.8 \\
\hline Latino/a & 1153 & 17.2 & 643 & 14.1 \\
\hline Asian-Am. & 201 & 3.0 & 119 & 2.6 \\
\hline Native Am. ${ }^{1}$ & 156 & 2.3 & 103 & 2.2 \\
\hline Multi-ethnic & 155 & 2.3 & 112 & 2.5 \\
\hline
\end{tabular}

Note. Except for total N, all N's and percentages are weighted by a normalized weight; small amounts of missing data on ethnicity cause the total to be less than the grand total.

1 Native American includes Alaskan and Pacific Island natives. 
Table 2: School Demographics

\begin{tabular}{|c|c|c|c|c|}
\hline Demographic & $\mathrm{N}$ & $\%$ & $\mathrm{~N}$ & $\%$ \\
\hline & $\begin{array}{l}\text { Fifth } \\
\text { Grade }\end{array}$ & & $\begin{array}{l}\text { Eighth } \\
\text { Grade }\end{array}$ & \\
\hline No. of Schools & 802 & ---- & 472 & ---- \\
\hline \multicolumn{5}{|l|}{ School Type } \\
\hline Public & 658 & 82.0 & 371 & 78.6 \\
\hline Private & 144 & 18.0 & 101 & 21.4 \\
\hline \multicolumn{5}{|l|}{ Enrollment } \\
\hline$<150$ & 33 & 4.1 & 15 & 3.2 \\
\hline 150 & 143 & 17.8 & 72 & 15.3 \\
\hline 300 & 270 & 33.7 & 97 & 20.6 \\
\hline 500 & 232 & 28.9 & 123 & 26.1 \\
\hline 750 and $\mathrm{Up}$ & 124 & 15.5 & 165 & 35.0 \\
\hline \multicolumn{5}{|l|}{$\%$ Minority } \\
\hline$<10 \%$ & 228 & 28.4 & 152 & 32.2 \\
\hline $10-24 \%$ & 135 & 16.8 & 110 & 23.3 \\
\hline $25 \%-49 \%$ & 137 & 17.1 & 94 & 19.9 \\
\hline $50 \%-75 \%$ & 88 & 11.0 & 52 & 11.0 \\
\hline$>75 \%$ & 214 & 26.7 & 64 & 13.6 \\
\hline
\end{tabular}


Table 3 Descriptives for Outcomes and Predictors

\begin{tabular}{|c|c|c|c|c|c|c|}
\hline & \multicolumn{2}{|c|}{$\underline{\text { Fifth Grade }}$} & \multicolumn{2}{|c|}{$\underline{\text { Eighth Grade }}$} & \multicolumn{2}{|c|}{ Eighth Changers } \\
\hline & Mean & S.D. & Mean & S.D. & Mean & S.D. \\
\hline \multicolumn{7}{|l|}{ Outcome } \\
\hline Reading ASC & 2.99 & .73 & 2.54 & .74 & 2.51 & .74 \\
\hline Math ASC & 2.91 & .77 & 2.63 & .89 & 2.64 & .89 \\
\hline \multicolumn{7}{|c|}{ Individual Predictors } \\
\hline Reading Ach. & 51.87 & 9.13 & 52.57 & 9.11 & 52.26 & 9.19 \\
\hline Math Ach. & 51.95 & 9.27 & 52.31 & 9.23 & 52.19 & 9.32 \\
\hline \multicolumn{7}{|c|}{$\underline{\text { School Predictors (means) }}$} \\
\hline Reading Ach. & 52.37 & 5.34 & 53.59 & 5.22 & 53.13 & 5.72 \\
\hline \multirow[t]{2}{*}{ Math Ach. } & 52.49 & 5.35 & 53.22 & 5.00 & 53.17 & 5.37 \\
\hline & $\mathrm{N}$ & $\%$ & $\mathrm{~N}$ & $\%$ & $\mathrm{~N}$ & $\%$ \\
\hline \multicolumn{7}{|c|}{ School Predictors (Percent) } \\
\hline \multicolumn{7}{|c|}{ School Type } \\
\hline Public & 658 & 82.0 & 371 & 78.6 & 322 & 93.9 \\
\hline Private & 144 & 18.0 & 101 & 21.4 & 21 & 6.1 \\
\hline \multicolumn{7}{|l|}{$\underline{\text { Enrollment }}$} \\
\hline $0-149$ & 33 & 4.1 & 15 & 3.2 & 6 & 1.7 \\
\hline $150-299$ & 143 & 17.8 & 72 & 15.3 & 27 & 7.9 \\
\hline $300-499$ & 270 & 33.7 & 97 & 20.6 & 62 & 18.1 \\
\hline $500-749$ & 232 & 28.9 & 123 & 26.1 & 91 & 26.5 \\
\hline$>750$ & 124 & 15.5 & 165 & 35.0 & 157 & 45.8 \\
\hline \multicolumn{7}{|l|}{$\%$ Minority } \\
\hline$<10 \%$ & 228 & 28.4 & 152 & 32.2 & 97 & 28.3 \\
\hline $10-25 \%$ & 135 & 16.8 & 110 & 23.3 & 75 & 21.9 \\
\hline $25-50 \%$ & 137 & 17.1 & 94 & 19.9 & 80 & 23.3 \\
\hline $50-75 \%$ & 88 & 11.0 & 52 & 11.0 & 48 & 14.0 \\
\hline$>75 \%$ & 214 & 26.7 & 64 & 13.6 & 43 & 12.5 \\
\hline
\end{tabular}

Note. Data on individual level data are all weighted. 
Table 4 Individual and School Effects

\begin{tabular}{|c|c|c|c|c|c|c|}
\hline & \multicolumn{2}{|c|}{$\underline{\text { Fifth Grade }}$} & \multicolumn{2}{|c|}{$\underline{\text { Eighth Grade }}$} & \multicolumn{2}{|c|}{ Eighth Changers } \\
\hline & Read. & Math. & Read. & Math & Read. & Math \\
\hline \multirow[t]{2}{*}{ Intraclass Correlation (ICC) } & .13 & .10 & .09 & .10 & .11 & .11 \\
\hline & \multicolumn{6}{|c|}{ Individual Level Variables } \\
\hline Gender & $.25^{*}$ & .01 & $.42 *$ & .01 & $.26^{*}$ & .04 \\
\hline SES & $-.32 *$ & -.19 & -.01 & -.19 & -.25 & -.08 \\
\hline SES x Achievement Interaction & $.39 *$ & .16 & .12 & .16 & .32 & .07 \\
\hline Reading Achievement & $.36^{*}$ & & $.43^{*}$ & & $.37 *$ & \\
\hline Math Achievement & & $.32 *$ & & $.32 *$ & & $.37 *$ \\
\hline \multirow[t]{2}{*}{ School Achievement Change } & & & & & -.01 & $.20 *$ \\
\hline & \multicolumn{6}{|c|}{ School Level Variables } \\
\hline Aggregate Reading Achievement & $-.10^{*}$ & & -.05 & & .02 & \\
\hline Aggregate Math Achievement & & -.05 & & -.05 & & -.07 \\
\hline Aggregate SES & .03 & -.05 & -.02 & -.05 & -.06 & -.08 \\
\hline School Size (Enrollment) & -.07 & -.02 & -.03 & -.02 & -.04 & .00 \\
\hline Percent Minority & .10 & .00 & $.06 *$ & .00 & $.07 *$ & -.04 \\
\hline Public or Private School & -.06 & -.01 & -.04 & -.01 & -.05 & -.01 \\
\hline
\end{tabular}

Note. Data on individual level data are all weighted. 
Figure 1: Reading Achievement vs. Reading ASC by Three Levels of Student SES

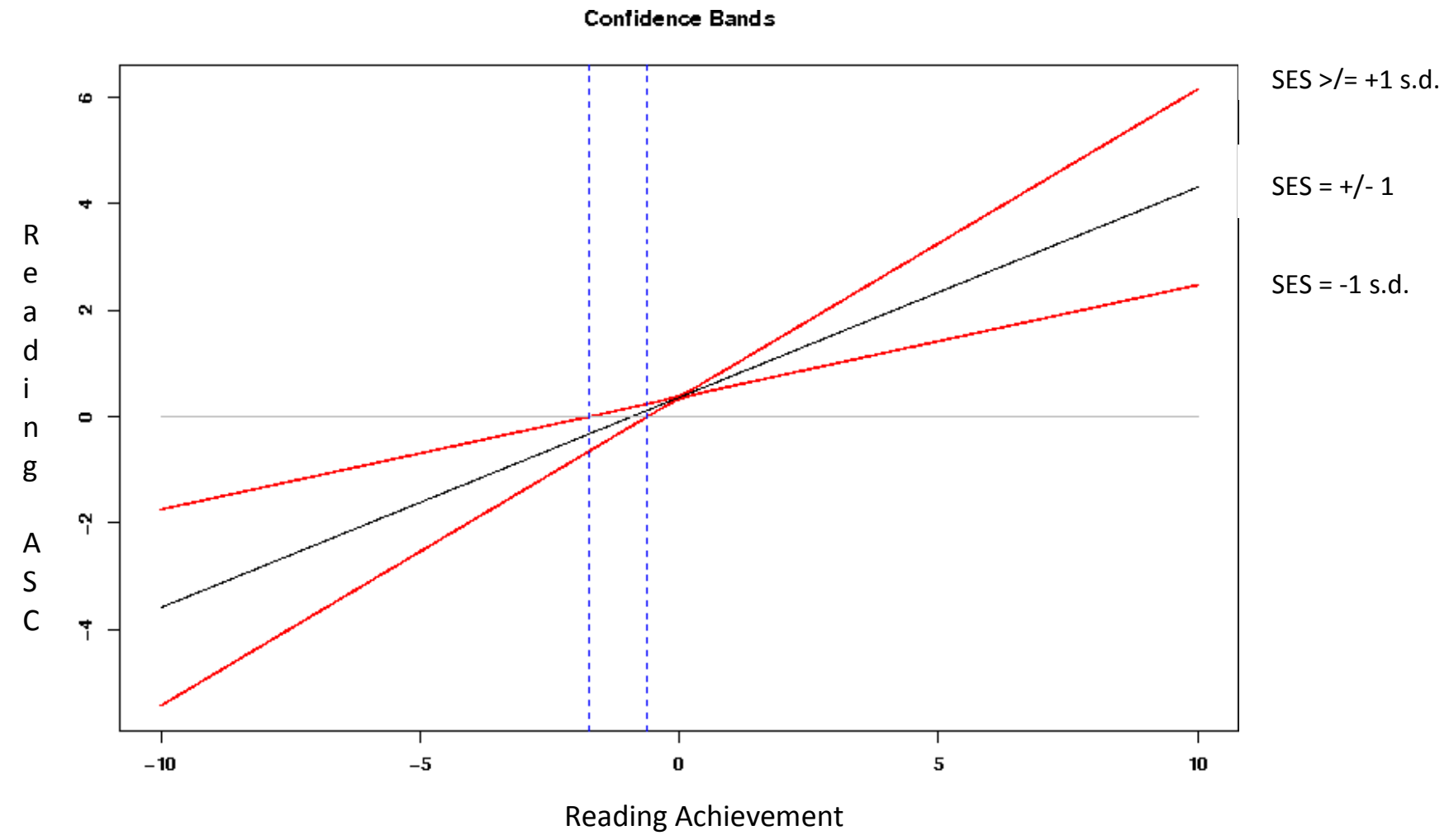

